\title{
Спортивное питание
}

УдК 612.063; 612.135

DOI: $10.14529 / h s m 19 s 116$

\section{ВЛИЯНИЕ БИОПРОДУКТА ИЗ МОЛОЧНОЙ СЫВОРОТКИ НА ОБМЕННЫЕ ПРОЦЕССЫ В СИСТЕМЕ МИКРОЦИРКУЛЯЦИИ КРОВИ}

\author{
Т.М. Брук, Ф.Б. Литвин, П.А. Терехов \\ Смоленская государственная академия фризической культуры, спорта и туризма, \\ е. Смоленск, Россия
}

\begin{abstract}
Цель исследования. Изучение влияния продукта молочной сыворотки на обменные процессы, характер и местные механизмы регуляции микроциркуляции крови у студентов, занимающихся легкой атлетикой. Материалы и методы. Влияние биопродуктов изучали на 32 легкоатлетах мужского пола. Исследование системы микроциркуляции проводили с помощью лазерного анализатора капиллярного кровотока «ЛАКК-М». Расчет всех показателей проводили с помощью специального пакета программ (версия 2.0.0.423, НПП «ЛАЗМА», Россия). Результаты. Установлено, что курсовое употребление биопродукта «Мультикомплекс MDX» повышает на 34 \% перфузию крови в микроциркуляторном русле и на 66 \% улучшает колеблемость эритроцитов, что, в конечном счете, повышает эффективность обменных процессов. Модуляция кровотока обеспечивается усиленной работой местных активных механизмов регуляции. Статистически надежное повышение на $42 \%$ отмечается со стороны эндотелий зависимого механизма, на 32 \% - миогенного и на $23 \%$ - нейрогенного. Вклад пассивных механизмов регуляции, обусловленных работой грудной клетки и сердечной мышцы, снижается. Физиологически активные вещества биопродукта участвуют в вазодилатации микрососудов, окислительно-восстановительных реакциях на клеточном уровне. Повышение на $22 \%$ содержания восстановленного кофермента NADH и снижение на $9 \%$ окисленного FAD свидетельствует о снижении активности митохондрий в отсутствие физических нагрузок и косвенно подтверждает полное восстановление энергетических запасов организма спортсменов. Заключение. Представленный материал свидетельствует об оптимизации обменных процессов в системе микроциркуляции крови под влиянием биопродукта «Мультикомплекс MDX».
\end{abstract}

Ключевые слова: биопродукт, микроциркуляџия, обмен веществ.

Введение. Современный студенческий спорт во многом заимствует структуру и направленность подготовки из профессионального спорта, где физические нагрузки протекают на фоне максимального использования функциональных ресурсов организма. С учетом не всегда сбалансированного и энергодостаточного питания студенческой молодежи это может негативно отражаться на здоровье, качестве жизни и профессиональной подготовке будущих специалистов народного хозяйства. Частые и объемные тренировки, особенно в предсоревновательный период, оставляют все меньше времени для отдыха и восстановления физической работоспособности [10]. Одним из важнейших факторов, обеспечивающих оптимальную адаптацию организма студентов-спортсменов к нагруз- кам, является питание. Конституциональные, генетические и биохимические особенности организма нацеливают специалистов на включение в питание эффективных, доказательно безопасных и финансово дешевых пищевых добавок, в разряд которых входят функционально активные вещества. К числу общепризнанных пищевых добавок относятся продукты пчеловодства [2], растениеводства [8], животноводства $[1,14,17]$. Меньшую признательность при высоком актопротекторном, эрготропном и иммуномодулирующем воздействии на организм спортсмена получили продукты из молочной сыворотки $[6,12,15]$.

Цель исследования. Изучить влияние продукта молочной сыворотки на обменные процессы, характер и местные механизмы ре- 


\section{Спортивное питание}

гуляции микроциркуляции крови у студентов, занимающихся легкой атлетикой.

Организация и методы исследования. В исследовании приняло участие 32 легкоатлета мужского пола. Из них 20 спортсменов составили экспериментальную группу и 12 спортсменов - контрольную группу. Спортсмены ЭГ на протяжении 30 дней по общепринятой схеме употребляли «Мультикомплекс MDX». Спортсмены КГ принимали плацебо. Исследование системы микроциркуляции проводили с помощью лазерного анализатора капиллярного кровотока «ЛАКК-М» («ЛАЗМА», РФ). Анализировали общепринятые показатели микроциркуляции: параметр микроциркуляции (ПМ, перф. ед.), среднее квадратическое отклонение (СКО, перф. ед.), амплитуду миогенных колебаний (Ам, перф. ед.), нейрогенных (Ан, перф. ед.), эндотелиальных (Аэ, перф. ед.), дыхательных (Ад, перф. ед.) и пульсовых колебаний (Ас, перф. ед.), а также содержание коферментов восстановленного никотинамидадениндинуклеотида (NADH усл. ед.) и окисленного флавинадениндинуклеотида (FAD, усл. ед.), их отношение FAD/NADH. Расчет всех показателей проводили с помощью специального пакета программ (версия 2.0.0.423, НПП «ЛАЗМА», Россия). Для обеспечения сбалансированного питания студентов на протяжении 30 дней использовали гомогенизированный продукт из молочной сыворотки (торговая марка «Мультикомплекс MDX»). Спортсмены контрольной группы принимали раствор пищевого крахмала в соответствующей дозе. Тестируемый продукт, полученный способом микробиологической переработки молочных сывороток (подсырной, творожной, казеиновой) с использованием промышленных культур молочнокислых микроорганизмов и последующим низкотемпературным сгущением, содержит гидролизованный белок молочной сыворотки, олигопептиды и 20 свободных аминокислот, глюкозу, галактозу, нуклеиновые кислоты, витамины: C, E, B, $\mathrm{B}_{2}$, PP, бета-каротин, эргостерин, фолиевую кислоту, эндосомальные ферменты молочнокислых бактерий, микроэлементы: $\mathrm{Ca}, \mathrm{Mg}, \mathrm{Cu}$, $\mathrm{Zn}, \mathrm{Mn}, \mathrm{Fe}$ и макроэлементы: K, Na.

Результаты исследования и их обсуждение. Тенденции на увеличение объема и интенсивности физических нагрузок, высокая плотность соревнований нередко являются причиной недостаточного восстановления спортсменов. На этом фоне развивается перенапряжение с возможностью перейти в перетренировку и преморбидное состояние. С этой целью для ускоренного восстановления организма использовали курсовое применение «Мультикомплекса MDX». Согласно полученным данным после приема биопродукта достоверно на $34 \%$ увеличилась интенсивность микроциркуляции ( $<<0,05)$. Повышение эффективности обменных процессов сопровождалось ростом на $66 \%$ величины уровня колеблемости эритроцитов (флакс) (см. таблицу). Повышение флакса происходит в результате улучшения работы регуляторных механизмов активного контроля микроциркуляции. Влияние активных и пассивных факторов на поток крови приводит к изменению скорости и концентрации потока эритроцитов, что, в свою очередь, вызывает модуляцию перфузии $[5,16]$. У спортсменов ЭГ отмечается увеличение амплитуды эндотелиальных, нейрогенных и миогенных ритмов на 42, 41 и $32 \%$. Из пассивных механизмов следует отметить скачкообразное снижение на $150 \%$ вклада в регуляцию респираторного ритма $(\mathrm{p}<0,05)$ и недостоверное повышение на 38 \% пульсовых колебаний.

Изучение особенностей формирования сосудисто-тканевых отношений в микроциркуляторном русле у спортсменов в условиях приема биопрепарата позволяет раскрыть закономерности участия физиологически активных соединений, входящих в состав «Мультикомплекса MDX», в энергетическом обмене клетки.

Использование в аппарате методики лазерной флуоресцентной диагностики позволяет изучить содержание восстановленного кофермента NADH и окисленного FAD. Наряду c участием в многочисленных метаболических процессах коферменты задействованы в окислительно-восстановительных реакциях. Глюкоза и жирные кислоты окисляются и выделяют энергию. Эта энергия запасается $\mathrm{NAD}^{+}$при его восстановлении до $\mathrm{NADH}$ в реакциях $\beta$-окисления жирных кислот, гликолиза и цикла трикарбоновых кислот. Поскольку $\mathrm{NAD}^{+}$синтезируется из аспартата и триптофана, входящих в состав «Мультикомплекса MDX», включение последнего в питание обеспечивает практически суточную норму данных аминокислот. По данным лазерной флуоресцентной диагностики у спортсменов ЭГ за время приема биопродукта содержание 
Показатели микроциркуляции у легкоатлетов после курсового приема «Мультикомплекса MDX» (M \pm m) Indicators of the microcirculation in athletes after the MDX Multicomplex (M $\pm m$ )

\begin{tabular}{|c|c|c|c|c|c|c|c|c|c|c|}
\hline $\begin{array}{l}\text { Группа } \\
\text { Group }\end{array}$ & $\begin{array}{c}\text { ПМ, } \\
\text { Перф. ед. } \\
\text { MP, perf. } \\
\text { units }\end{array}$ & $\begin{array}{c}\text { СКО, } \\
\text { перф. ед. } \\
\text { SD, perf. } \\
\text { units }\end{array}$ & $\begin{array}{c}\text { Аэ, } \\
\text { перф. ед } \\
\text { Ae, perf. } \\
\text { units }\end{array}$ & $\begin{array}{c}\text { Ан, } \\
\text { перф. ед. } \\
\text { An, perf. } \\
\text { units }\end{array}$ & $\begin{array}{c}\text { Ам, } \\
\text { перф. ед. } \\
\text { Am, perf. } \\
\text { units }\end{array}$ & $\begin{array}{c}\text { Ад, } \\
\text { перф. ед. } \\
\text { Ar, perf. } \\
\text { units }\end{array}$ & $\begin{array}{c}\text { Ac, } \\
\text { перф. ед. } \\
\text { Ap, perf. } \\
\text { units }\end{array}$ & $\begin{array}{c}\text { NADH, } \\
\text { усл. ед. } \\
\text { NADH, } \\
\text { cond. } \\
\text { units }\end{array}$ & $\begin{array}{l}\text { FAD, } \\
\text { усл. ед. } \\
\text { FAD, } \\
\text { cond. } \\
\text { units }\end{array}$ & $\begin{array}{l}\text { FAD } / \\
\text { NADH }\end{array}$ \\
\hline \multicolumn{11}{|c|}{$\begin{array}{l}\text { До применения «Мультикомплекса MDX» } \\
\text { Prior to the use of the MDX Multicomplex }\end{array}$} \\
\hline $\begin{array}{l}\text { ЭГ } \\
\mathrm{EG}\end{array}$ & $\begin{array}{c}10,6 \pm \\
0,42\end{array}$ & $\begin{array}{c}1,57 \pm \\
0,21\end{array}$ & $\begin{array}{c}14,68 \pm \\
1,36\end{array}$ & $\begin{array}{c}13,25 \pm \\
1,40\end{array}$ & $\begin{array}{c}11,9 \pm \\
0,85\end{array}$ & $\begin{array}{c}8,98 \pm \\
0,68\end{array}$ & $\begin{array}{c}6,01 \pm \\
0,29\end{array}$ & $\begin{array}{c}3,16 \pm \\
0,07\end{array}$ & $\begin{array}{c}0,93 \pm \\
0,03\end{array}$ & $\begin{array}{c}0,30 \pm \\
0,02\end{array}$ \\
\hline $\begin{array}{l}\mathrm{K} \Gamma \\
\mathrm{CG}\end{array}$ & $\begin{array}{c}9,55 \pm \\
0,46\end{array}$ & $\begin{array}{c}0,98 \pm \\
0,08\end{array}$ & $\begin{array}{c}11,09 \pm \\
1,10\end{array}$ & $\begin{array}{c}13,45 \pm \\
1,28\end{array}$ & $\begin{array}{c}12,4 \pm \\
0,90\end{array}$ & $\begin{array}{c}4,46 \pm \\
0,27\end{array}$ & $\begin{array}{c}8,03 \pm \\
0,40\end{array}$ & $\begin{array}{c}2,87 \pm \\
0,06\end{array}$ & $\begin{array}{c}0,89 \pm \\
0,03 \\
\end{array}$ & $\begin{array}{c}0,39 \pm \\
0,02\end{array}$ \\
\hline \multicolumn{11}{|c|}{$\begin{array}{c}\text { После применения «Мультикомплекса MDX» } \\
\text { After the use of the MDX Multicomplex }\end{array}$} \\
\hline $\begin{array}{l}\text { ЭГ } \\
\text { EG }\end{array}$ & $\begin{array}{l}14,2 \pm \\
0,61^{*}\end{array}$ & $\begin{array}{c}2,61 \pm \\
0,39^{*}\end{array}$ & $\begin{array}{c}20,82 \pm \\
2,23^{*}\end{array}$ & \begin{tabular}{|c|}
$18,73 \pm$ \\
$1,45^{*}$
\end{tabular} & $\begin{array}{c}15,7 \pm \\
1,23^{*}\end{array}$ & $\begin{array}{c}3,59 \pm \\
0,12^{*}\end{array}$ & $\begin{array}{c}8,27 \pm \\
0,31^{*}\end{array}$ & $\begin{array}{c}3,87 \pm \\
0,09^{*}\end{array}$ & $\begin{array}{c}1,01 \pm \\
0,04\end{array}$ & $\begin{array}{c}0,28 \pm \\
0,01\end{array}$ \\
\hline $\begin{array}{l}\mathrm{K} \Gamma \\
\mathrm{KG}\end{array}$ & $\begin{array}{c}9,52 \pm \\
0,47\end{array}$ & $\begin{array}{c}2,18 \pm \\
0,33 \bullet\end{array}$ & $\begin{array}{c}13,67 \pm \\
1,41\end{array}$ & $\begin{array}{c}16,24 \pm \\
1,79\end{array}$ & $\begin{array}{c}13,0 \pm \\
1,04\end{array}$ & $\begin{array}{l}7,40 \pm \\
0,35 \bullet\end{array}$ & $\begin{array}{c}13,4 \pm \\
1,05 \bullet\end{array}$ & $\begin{array}{l}1,90 \pm \\
0,04 \bullet\end{array}$ & $\begin{array}{c}0,89 \pm \\
0,03\end{array}$ & $\begin{array}{c}0,53 \pm \\
0,05 \bullet\end{array}$ \\
\hline
\end{tabular}

Примечание. * - ${ }^{*}<0,05$ изменения достоверны относительно исходного состояния у спортсменов экспериментальной группы; - $-\mathrm{p}<0,05$ изменения достоверны относительно исходного состояния у спортсменов контрольной группы.

Note. ${ }^{*}-\mathrm{p}<0.05$ the changes are significant for the initial state in athletes from the experimental group; $-\mathrm{p}<0.05$ the changes are significant for the initial state in athletes from the control group.

NADH повышается на $22 \%$ (p $<0,05)$, a FAD на $9 \%$. Отношение FAD/NADH за время приема биопродукта снижается на 7 \%. Как отмечает В.Н. Карнаухов [3], это отношение является важной частью окислительновосстановительного состояния клетки - мерой ее метаболической активности - и уровня жизнедеятельности клетки.

В ходе исследования показано, что у спортсменов КГ за время приема плацебо показатели микрокровотока, механизмы, его обеспечивающие, и состояние обменных процессов развиваются иначе. В частности, величина перфузии практически не изменяется (см. таблицу), показатель флакса достоверно повышается на $122 \%(\mathrm{p}<0,05)$. Основными механизмами регуляции кровотока являются внешние механизмы, обусловленные присасывающим действием грудной клетки и пульсовыми колебаниями крупных сосудов. В частности, Ад колебаний достоверно повышается на $66 \%$, а Ас - на $67 \%(\mathrm{p}<0,05)$. Вклад активных механизмов незначительный при недостоверном усилении амплитуды эндотелиальных, нейрогенных и миогенных колебаний на 23, 21 и $4 \%$ соответственно ( $p>0,05)$. Данный факт отражает снижение эффективности в работе микроциркуляторного русла (В.И. Козлов и др. [4]). При исходно пониженных величинах NADH и FAD у спортсме- нов КГ за время исследования показатель NADH снижается на $51 \%(\mathrm{p}<0,05)$, a FAD не изменяется. Отношение FAD / NADH повышается на $36 \%(\mathrm{p}<0,05)$.

Выполненное исследование продемонстрировало, что использование в качестве пищевой добавки «Мультикомплекса MDX» улучшает местный кровоток и ускоряет восстановление энергетических запасов. На наш взгляд, рост интенсивности микроциркуляции связан с высоким содержанием L-аргинина в биопродукте. В клетках эндотелия кровеносных сосудов оксид азота NO производится непрерывно в ходе ферментативной реакции аминокислоты L-аргинина с молекулярным кислородом. Реакция идет под действием специального фермента, называемого NOсинтазой, в присутствии кофактора реакции NADPH - никотинамидадениндинуклеотидфосфата и некоторых других $[11,13]$. Далее NO диффундирует в клетки гладкой мускулатуры кровеносных сосудов, окружающих эндотелий, и активирует цепь биологических реакций, вызывающих расслабление мускулатуры сосудов и увеличение кровотока. В свою очередь скорость производства NO эндотелием пропорциональна модулю напряжения сдвига, которая увеличивается по мере усиления скорости кровотока за счет нарастания величины перфузии в микроциркуляторном 


\section{Спортивное питание}

русле спортсменов ЭГ [9]. Кроме этого, часть L-аргинина участвует в синтезе белков. Эргогенные аминокислоты, входящие в состав «Мультикомплекса MDX», активно участвуют в энергетическом обмене. Из общего количества энергии, образующейся в организме, на долю аминокислот приходится более $10 \%$.

Необходимо отметить, что разные аминокислоты имеют отличающиеся пункты («ворота») входа в цикл Кребса, а следовательно, и разную эффективность в качестве субстратов энергообеспечения. Уже на начальном этапе цикла Кребса аминокислоты серин, аланин, глицин, цистеин способны метаболизироваться в пируват, который затем окисляется пируватдегидрогеназой до ацетил-коэнзима А, последний дальше вступает в реакции цикла Кребса. На стадии цикла Кребса, в которой образуется $\alpha$-кетоглутарат, «включается» аргинин. На уровне синтеза сукцинил-коэнзима А из альфа-кетоглутарата в цикл Кребса встраивается глутамат, в который метаболизируются гистидин и пролин. На уровне Сукцинил-SКоа в цикл внедряются такие аминокислоты, как метионин, валин, треонин, изолейцин. В пируват и Ацетил-S-Коа метаболизируется аминокислота триптофан.

Кроме триптофана в Ацетил-S-Коа превращаются аминокислоты лейцин, изолейцин и лизин. Наиболее быстро в энергетический обмен вступают аминокислоты с разветвленной цепью (валин, лейцин, изолейцин). Во многом это связано с наличием в митохондриальных мембранах специфических переносчиков, обеспечивающих быстрое поступление этих аминокислот внутрь митохондрий без предварительной метаболической трансформации в цитозоле. Благодаря высокой скорости и мощности включения в ресинтез АТФ именно экзогенные аминокислоты с разветвленной цепью могут предотвращать катаболизм мышечных белков при энергодефиците из-за предельно переносимых длительных физических нагрузок. Дополнительно лейцин, валин и изолейцин участвуют в анаболизме мышечных белков и способствуют увеличению мышечной массы в целом [7]. На сравнительно быстрое восстановление энергетических запасов в организме спортсменов ЭГ указывает и величина отношения $\mathrm{FAD} / \mathrm{NADH}$, которая на 89 \% меньше по сравнению с показателем в КГ. Если соотношение FAD/NADH увеличивается, то состояние митохондрии расценивается как активное. Это сопровождается высо- ким содержанием АДФ, высоким содержанием субстрата и интенсивным дыханием [3], что в целом свидетельствует о неполном восстановлении организма спортсменов КГ после физической нагрузки.

Заключение. Использование в качестве метаболического и эргогенного продукта «Мультикомплекса MDX» повышает перфузию крови, оптимизирует работу местных механизмов регуляции в системе микроциркуляции, обеспечивает более быстрое восстановление энергетических запасов организма спортсменов.

\section{Литература \\ 1. Анализ молекулярных механизмов} фармакологического действия препарата «САЙТАРИН» на клеточно-тканевой метаболизм в условиях гипоксии / Р.М. Файзиев // Материаль IX Междунар. науч. конф. студентов, аспирантов и молодых ученых «Ломоносов-2002», 2002. - С. 60.

2. Инновачионное спортивное питание на основе комплексного применения апифитопродукиии тенториум / В.Н. Ким, И.П. Хисматуллина, И.Г. Аксенова // Материалы I Междунар. форума «Большая наука большому спорту», 2016. - С. 278-297.

3. Карнаухов, В.Н. Люминесиентный анализ клеток: учеб. пособие / В.Н. Карнаухов. Пушино: ИБК РАН, 2002. - $131 \mathrm{c}$.

4. Козлов, В.И. Лазерная фотостимуляция кровотока в пиальных микрососудах / В.И. Козлов, Ф.Б. Литвин, С.М. Рыжакин // Тихоокеанский мед. журнал. - 2016. - № 2. C. 90-93.

5. Крупаткин, А.И. Функииональная диагностика состояния микроциркуляторнотканевых систем: колебания, информация, нелинейность: рук. для врачей / А.И. Крупаткин, В.В. Сидоров. - М.: ЛИБРОКОМ, 2014. $498 \mathrm{c}$.

6. Литвин, Ф.Б. Комплексное применение природных биостимуляторов в тренировочном процессе высококвалифицированных легкоатлетов / Ф.Б. Литвин, Т.М. Брук, П.А. Терехов и др. // Человек. Спорт. Медичина. 2018. - T. 18, № S. - C. 135-139. DOI: 10.14529/hsm18s19

7. Очерки спортивной фармакологии. T. 2: Векторы фармакопротекции / под ред. Н.Н. Каркищенко и В.В. Уйба. - М.; СПб.: Айсинг, 2014. - 448 c.

8. Хасина, Э.И. Влияние эхиноцеи пур- 
пурной на физическую работоспособность при экстремальном действии холода / Э.И. Хасина, В.М. Фисенко // Тихоокеанский мед. журнал. 2014. - № 1. - C. 19-23.

9. Шадрина, Н.Х. Влияние конценттрацчии кислорода на местную регулящию кровотока напряжением сдвига / Н.Х. Шадрина // Микроциркуляция и регионарное кровообращзение. - 2016. - № 2. - C. 60-64. DOI: 10.24884/1682-6655-2016-15-2-60-64

10. Шестопалова, А.Е. Диагностика и общие приничипь коррекции нутритивнометаболического статуса у спортсменов высокой квалификации: метод. рек. / А.Е. Шестопалова, Э.С. Токаев, А.С. Самойлов. - М.: ФНКЦСМ ФМБА России, 2015. - 67 c.

11. Bachmann, S. Nitric oxide in the kidney: synthesis, localization, and function / S. Bachmann, P. Mundel // Am. J. Kidney Dis. - 1994. Vol. 24. - P. 112-129.

12. Buttstedt, A. Origin and function of the major royal jelly proteins of the honeybee (Apis mellifera) as members of the yellow gene family / A. Buttstedt, R.F. Moritz, S. Erler // Biological Reviews of the Cambridge Philosophical Society. - 2014. - Vol. 89 (2). - P. 255-269. DOI: $10.1111 / \mathrm{brv} .12052$
13. Cropley, M. The Effects of Rhodiola rosea L. Extract on Anxiety, Stress, Cognition and Other Mood Symptoms / M. Cropley, A.P. Banks, J. Boyle // Phytotherapy Research. - 2015. Vol. 29, no. 12. - P. 1934-1939. DOI: 10.1002/ ptr. 5486

14. Flachs, $H$. The effect of $n-3$ fatty acids on glucose homeostasis and insulin sensitivity / H. Flachs, M. Rossmeisl, J. Kopecky // Physiol Res. - 2014. - Vol. 63. - P. 93-118.

15. Hadi, A. Royal jelly is an effective and relatively safe alternative approach to blood lipid modulation: A meta-analysis / A. Hadi, A. Najafgholizadeh, E. Smadi Aydenlu // Journal of Functional Foods. - 2018. - Vol. 41. - P. 202-209. DOI: 10.1016/j.jff.2017.12.005

16. Pries, A.R. Physiological basis of the microcirculation: vascular adaptation / A.R. Pries // Klin. Monbl. Augenheikd. - 2015. - Vol. 232, no. 2. - P. 127.

17. Wang, Z.Y. Pharmacological Effects of Active Components of Chinese Herbal Medicine in the Treatment of Alzheimer's Disease: a review / Z.Y. Wang, J.G. Liu, H. Li et al. // American Journal of Chinese Medicine. - 2016. Vol.44, no. 8. - P. 1525-1541. DOI: $10.1142 / \mathrm{S} 0192415 \times 16500853$

Брук Татьяна Михайловна, доктор биологических наук, профессор, заведующая кафедрой биологических дисциплин, Смоленская государственная академия физической культуры, спорта и туризма. 214018, г. Смоленск, пр. Гагарина, 23. E-mail: bryktmcenter@rambler.ru, ORCID: 0000-0003-1023-6642.

Литвин Федор Борисович, доктор биологических наук, профессор, доцент кафедры биологических дисциплин, Смоленская государственная академия физической культуры, спорта и туризма. 214018, г. Смоленск, пр. Гагарина, 23. E-mail: bf-litvin@yandex.ru, ORCID: 0000-0002-2281-8757.

Терехов Павел Александрович, кандидат биологических наук, старший преподаватель кафедры биологических дисциплин, Смоленская государственная академия физической культуры, спорта и туризма. 214018, г. Смоленск, пр. Гагарина, 23. E-mail: terechov_86@mail.ru, ORCID: 0000-0003-3579-6048.

Поступила в редакцию 30 апреля 2019 z. 


\title{
EFFECT OF A WHEY-BASED BIOPRODUCT ON METABOLIC PROCESSES IN THE MICROCIRCULATION
}

\author{
T.M. Bruk, bryktmcenter@rambler.ru, ORCID: 0000-0003-1023-6642, \\ F.B. Litvin, bf-litvin@yandex.ru, ORCID:0000-0002-2281-8757, \\ P.A. Terekhov, terechov_86@mail.ru, ORCID: 0000-0003-3579-6048 \\ Smolensk State Academy of Physical Culture, Sports and Tourism, Smolensk, Russian Federation
}

\begin{abstract}
Aim. The article deals with the effect of a whey-based product on the metabolic processes, character, and local mechanisms of the microcirculation in athletes involved in track-and-field athletics. Materials and methods. 32 male athletes participated in the study. The microcirculation was studied with the help of the LAKK-M laser analyzer. The calculations were conducted by using a special software package (version 2.0.0.423, LAZMA, Russia). Results. It is established that a course of the MDX Multicomplex bioproduct increases blood perfusion in the microcirculatory bloodstream by $34 \%$ and erythrocyte fluctuation by $66 \%$, which improve the efficiency of metabolic processes. Bloodstream modulation is provided by the enhanced performance of the local active regulatory mechanisms. A statistically significant increase of $42 \%$ is registered in the endothelium-dependent mechanism, the increase of $32 \%$ and $23 \%$ is found in the myogenic and neurogenic mechanisms respectively. The contribution of the passive regulatory mechanisms reduces as a result of chest and heart muscle performance. The physiologically active substances of the bioproduct are involved in the vasodilation of microvessels and redox reactions at the cellular level. A $22 \%$ increase in NADH reduced coenzyme and a $9 \%$ decrease in FAD oxidized coenzyme indicate a decrease in mitochondrial activity in the absence of physical exertion and, indirectly, confirm the complete restoration of the energy reserves. Conclusion. The data obtained proves the optimization of metabolic processes in the microcirculation as an effect of the MDX Multicomplex bioproduct.
\end{abstract}

Keywords: bioproduct, microcirculation, metabolism.

\section{References}

1. Fayziev R.M. [Analysis of the Molecular Mechanisms of the Pharmacological Action of the Drug Saytarin on Cell-Tissue Metabolism under Hypoxic Conditions]. Mater. IX Mezhdunar. nauch. konf. studentov, aspirantov i molodykh uchenykh "Lomonosov-2002" [Materials of the IX International Scientific Conference of Students, Postgraduates and Young Scientists Lomonosov-2002], 2002, p. 60. (in Russ.)

2. Kim V.N., Khismatullina I.P., Aksenova I.G. [Innovative Sports Nutrition Based on the Integrated Application of Apifitoproduktovoy Tentorium]. Materialy I Mezhdunar. foruma "Bol'shaya nauka bol'shomu sportu” [Materials of the I International Forum Big Science for Big Sport], 2016, pp. 278-297. (in Russ.)

3. Karnaukhov V.N. Lyuminestsentnyy analiz kletok [Luminescent Cell Analysis]. Pushchino, 2002. $131 \mathrm{p}$.

4. Kozlov V.I., Litvin F.B., Ryzhakin S.M. [Laser Photostimulation of Blood Flow in the Pial Microvessels]. Tikhookeanskiy meditsinskiy zhurnal [Pacific Medical Journal], 2016, no. 2. pp. 90-93. (in Russ.) DOI: 10.17238/PmJ1609-1175.2016.2.90-93

5. Krupatkin A.I., Sidorov V.V. Funktsional'naya diagnostika sostoyaniya mikrotsirkulyatornotkanevykh sistem: kolebaniya, informatsiya, nelineynost': rukovodstvo dlya vrachey [Functional Diagnostics of the State of Microcirculatory-Tissue Systems. Oscillations, Information, Nonlinearity]. Moscow, 2014. $498 \mathrm{p}$.

6. Litvin F.B., Bruk T.M., Terekhov P.A., Osipova N.V., Kosoryghina K.Yu. Comprehensive Application of Natural Biostimulators in the Training of Elite Athletes. Human. Sport. Medicine, 2018, vol. 18, no. S, pp. 135-139. (in Russ.) DOI: 10.14529/hsm18s19 
7. Karkishchenko N.N., Ujba V.V. (Eds.) Ocherki sportivnoy farmakologii. T. 2. Vektory farmakoprotektsii [Sketches of Sports Pharmacology. Vol. 2. Pharmacoprotection Vectors]. St. Petersburg, Icing Publ., 2014. 448 p.

8. Khasina E.I., Fisenko V.M. [The Effect of Echinacea Purpurea on Physical Performance During Extreme Cold Exposure]. Tikhookeanskiy meditsinskiy zhurnal [Pacific Medical Journal], 2014, no. 1, pp. 19-23. (in Russ.)

9. Shadrina N.Kh. [The Effect of Oxygen Concentration on Local Regulation of Blood Flow by Shear Stress]. Mikrotsirkulyatsiya i regionarnoye krovoobrashcheniye [Microcirculation and Regional Circulation], 2016, no. 2, pp. 60-64. (in Russ.) DOI: 10.24884/1682-6655-2016-15-2-60-64

10. Shestopalova A.E., Tokaev E.S., Samoylov A.S. Diagnostika i obshchiye printsipy korrektsii nutritivno-metabolicheskogo statusa u sportsmenov vysokoy kvalifikatsii [Diagnostics and General Principles of Correction of the Nutritional-Metabolic Status of Highly Qualified Athletes]. Moscow, FNKTSSM FMBA Russia Publ., 2015. 67 p.

11. Bachmann S., Mundel P. Nitric Oxide in the Kidney: Synthesis, Localization, and Function. Am. J. Kidney Dis., 1994, vol. 24, pp. 112-129. DOI: 10.1016/S0272-6386(12)80170-3

12. Buttstedt A., Moritz R.F., Erler S. Origin and Function of the Major Royal Jelly Proteins of the Honeybee (Apis Mellifera) as Members of the Yellow Gene Family. Biological Reviews of the Cambridge Philosophical Society, 2014, vol. 89 (2), pp. 255-269. DOI: 10.1111/brv.12052

13. Cropley M., Banks A.P., Boyle J. The Effects of Rhodiola Rosea L. Extract on Anxiety, Stress, Cognition and Other Mood Symptoms. Phytotherapy Research, 2015, vol. 29, no. 12, pp. 1934-1939. DOI: $10.1002 / \mathrm{ptr} .5486$

14. Flachs H., Rossmeisl M., Kopecky J. The Effect of n-3 Fatty Acids on Glucose Homeostasis and Insulin Sensitivity. Physiol Res, 2014, vol. 63, pp. 93-118.

15. Hadi A., Najafgholizadeh A., Smadi Aydenlu E. Royal Jelly is an Effective and Relatively Safe Alternative Approach to Blood Lipid Modulation: A Meta-Analysis. Journal of Functional Foods, 2018, vol. 41, pp. 202-209. DOI: 10.1016/j.jff.2017.12.005

16. Pries A.R. Physiological Basis of the Microcirculation: Vascular Adaptation. Klin. Monbl. Augenheikd., 2015, vol. 232, no. 2, p. 127. DOI: 10.1055/s-0034-1383394

17. Wang Z.Y., Liu J.G., Li H. et al. Pharmacological Effects of Active Components of Chinese Herbal Medicine in the Treatment of Alzheimer's Disease: a Review. American Journal of Chinese Medicine, 2016, vol. 44, no. 8, pp. 1525-1541. DOI: 10.1142/S0192415X16500853

Received 30 April 2019

\section{ОБРАЗЕЦ ЦИТИРОВАНИЯ}

Брук, Т.М. Влияние биопродукта из молочной сыворотки на обменные процессы в системе микроциркуляции крови / Т.М. Брук, Ф.Б. Литвин, П.А. Терехов // Человек. Спорт. Медицина. - 2019. - Т. 19, № S1. - C. 121-127. DOI: 10.14529/hsm19s116

\section{FOR CITATION}

Bruk T.M., Litvin F.B., Terekhov P.A. Effect of a Whey-Based Bioproduct on Metabolic Processes in the Microcirculation. Human. Sport. Medicine, 2019, vol. 19, no. S1, pp. 121-127. (in Russ.) DOI: 10.14529/hsm19s 116 